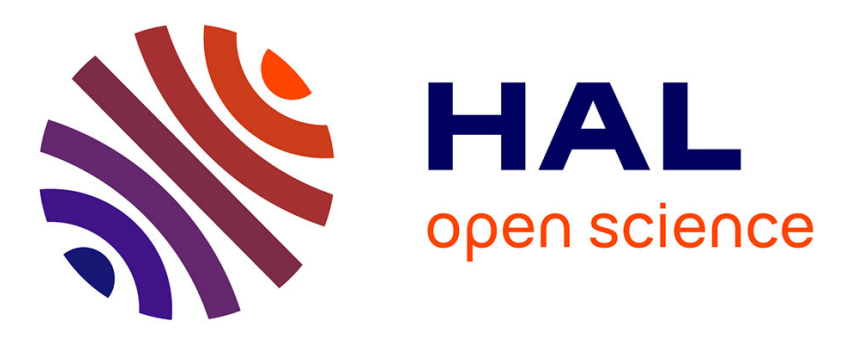

\title{
Simulation and design of a multistage 10W Thulium-doped double clad silica fiber amplifier at 2050nm
}

Clément Romano, Robert E Tench, Yves Jaouën, Glen M Williams

\section{- To cite this version:}

Clément Romano, Robert E Tench, Yves Jaouën, Glen M Williams. Simulation and design of a multistage 10W Thulium-doped double clad silica fiber amplifier at 2050nm. SPIE Photonics West (SPIE PW 17), Jan 2017, San Fransisco, United States. hal-01677051

\section{HAL Id: hal-01677051 \\ https://hal.science/hal-01677051}

Submitted on 7 Jan 2018

HAL is a multi-disciplinary open access archive for the deposit and dissemination of scientific research documents, whether they are published or not. The documents may come from teaching and research institutions in France or abroad, or from public or private research centers.
L'archive ouverte pluridisciplinaire HAL, est destinée au dépôt et à la diffusion de documents scientifiques de niveau recherche, publiés ou non, émanant des établissements d'enseignement et de recherche français ou étrangers, des laboratoires publics ou privés. 


\title{
Simulation and design of a multistage 10W Thulium-doped double clad silica fiber amplifier at $2050 \mathrm{~nm}$
}

\author{
Clément Romano*ac, Robert E. Tench ${ }^{\mathrm{b}}$, Yves Jaouën ${ }^{\mathrm{c}}$, Glen M. Williams ${ }^{\mathrm{a}}$ \\ ${ }^{a}$ Cybel LLC, 4715B Eisenhower Avenue, Alexandria, VA 22304; ${ }^{b}$ Cybel LLC, 1195 Pennsylvania \\ Avenue, Bethlehem, PA USA 18018; 'Institut Télécom/Télécom ParisTech, 46 Rue Barrault, 75634, \\ Paris France \\ *clement.romano@cybel-llc.com,www.cybel-1lc.com
}

\begin{abstract}
A careful comparison of experiment and theory is important both for basic research and systematic engineering design of Thulium fiber amplifiers operating in the $2 \mu \mathrm{m}$ region for applications such as LIDAR or spectroscopy (e.g. $\mathrm{CO}_{2}$ atmospheric absorption at $2051.4 \mathrm{~nm}$ ). In this paper we report the design and performance of a multistage high-power PM Tm-doped fiber amplifier, cladding pumped at $793 \mathrm{~nm}$. The design is the result of a careful comparison of numerical simulation, based on a three level model including ion-ion interactions, and experiment. Our simulation model is based on precise measurements of the cross sections and other parameters for both 6 and $10 \mu \mathrm{m}$ core diameter fibers. Good agreement for several single and multistage amplifier topologies and operating conditions will be presented. Origins of the difference between theory and experiment are discussed, with emphasis on the accuracy of the cross sections and the cross relaxation parameters. Finally based on our simulation tool, we will demonstrate a design with an output power greater than $10 \mathrm{~W}$ for a multistage amplifier with a single-frequency signal at $2050 \mathrm{~nm}$. The power stage was constructed with a $6 \mu \mathrm{m}$ active fiber showing a $64 \%$ optical slope efficiency. The output power is found to be within $5 \%$ of the simulated results and is limited only by the available launched pump power of $\sim 24 \mathrm{~W}$. No stimulated Brillouin scattering is observed at the highest output power level for an active fiber well thermalized.
\end{abstract}

Keywords: Single frequency fiber amplifier, thulium, cross section, Brillouin, multistage, simulation

\section{INTRODUCTION}

A careful comparison of experiment and theory is important both for basic research and systematic engineering design of Thulium fiber amplifiers operating in the $2 \mu \mathrm{m}$ region. Applications include LIDAR or spectroscopy, such as $\mathrm{CO}_{2}$ atmospheric absorption at $2051.4 \mathrm{~nm}{ }^{1}$. Currently the state of modeling for Tm-doped fiber (TDF) amplifiers is not nearly as advanced as the state of modeling for Erbium-doped fiber amplifiers ${ }^{2-5}$. Therefore a systematic comparison of simulation and experiment is important for the development of models for TDF amplifiers. So far only a few studies of the accuracy of Thulium models in silica fibers have been performed ${ }^{6-8}$ and none of them focus on $793 \mathrm{~nm}$ cladding pumped TDF amplifiers emitting around 2 microns.

In this paper we report the design and performance of two $2050 \mathrm{~nm}$ multistage high-power TDF amplifiers that are cladding pumped at $793 \mathrm{~nm}$. The design is the result of a careful comparison of numerical simulation, based on a three level model including ion-ion interactions, and experiment. We present first our simulation tool and then different setups with their experimental results and comparisons to simulation.

\section{MODEL}

Our simulation model is based on a three level representation of the Thulium ion (Figure 1). This Thulium model was originally introduced in a paper by S.D. Jackson ${ }^{9}$; it takes in account only the four first levels with the main processes involved in highly Thulium doped alumino-silica fibers. The ${ }^{3} \mathrm{H}_{5}$ level is neglected because of its short lifetime. Only nonradiative decay $\left(\boldsymbol{\tau}_{1}^{n r} \& \boldsymbol{\tau}_{3}^{n r}\right)$ remains in the model since the radiative lifetimes $\left(\sim 700 \mu \mathrm{s}\right.$ for ${ }^{3} \mathrm{H}_{4}, \sim 4.6 \mathrm{~ms}$ for $\left.{ }^{3} \mathrm{~F}_{4}{ }^{10}\right)$ are long in comparison to the non-radiative decay. The parameters $\alpha_{01} \& g_{10}^{*}$ represent the core absorption and gain of the lasing level, presented later in Figure 2. The pump absorption in the cladding, represented by the parameter $\alpha_{03}$, is considered to be constant for a monochromatic pump. Only the highest probability ion-ion processes are considered: the well-known

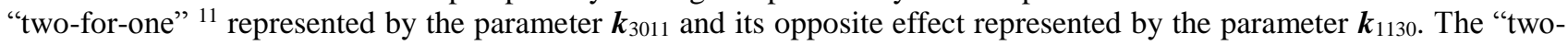


for-one" process is a cross relaxation interaction which allows two Thulium ions to reach the ${ }^{3} \mathrm{~F}_{4}$ level by pumping the ${ }^{3} \mathrm{H}_{4}$ level with one photon, resulting in a doubled quantum efficiency.

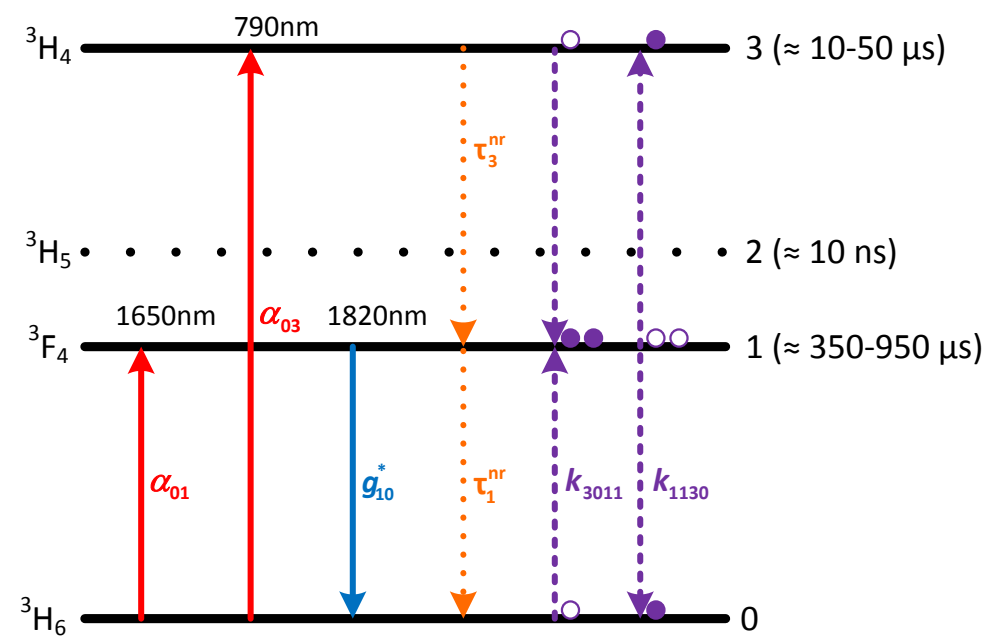

Figure 1: Simplified three level model of the Thulium ion.

The simulation tool relies on the precision of the physical model, presented above in ${ }^{9}$, and also on measurements of the different TDF parameters. It is essential for the accuracy of the model to use measured parameters for the individual TDFs under study. Measurements of the absorption, done on $6 \& 10 \mu \mathrm{m}$ core diameter Thulium doped fibers (provided by iXBlue Photonics - Lannion, France; labelled IX6 and IX10 in this paper), using a supercontinuum source, an optical spectrum analyzer (OSA), and a cutback method on short samples were performed. The IX6 fiber gain was determined using the emission cross section measured on the same fiber by W. Renard ${ }^{12}$. The absorption and gain coefficients for the 1400 $2200 \mathrm{~nm}$ wavelength region are shown in Figure 2 for the IX6 fiber. The lifetime of the ${ }^{3} \mathrm{~F}_{4}$ level of six commercial fibers available in our lab were measured using an in-band pulsed source while looking at the backward light. Values were extracted from the decay curves using a traditional two exponential fit ${ }^{12-15}$, see Figure 3 . The long decay values were found to be spread between 500 and $750 \mu \mathrm{s}$. Other parameters used were taken from the literature. All the parameters are summarized in Table 1.

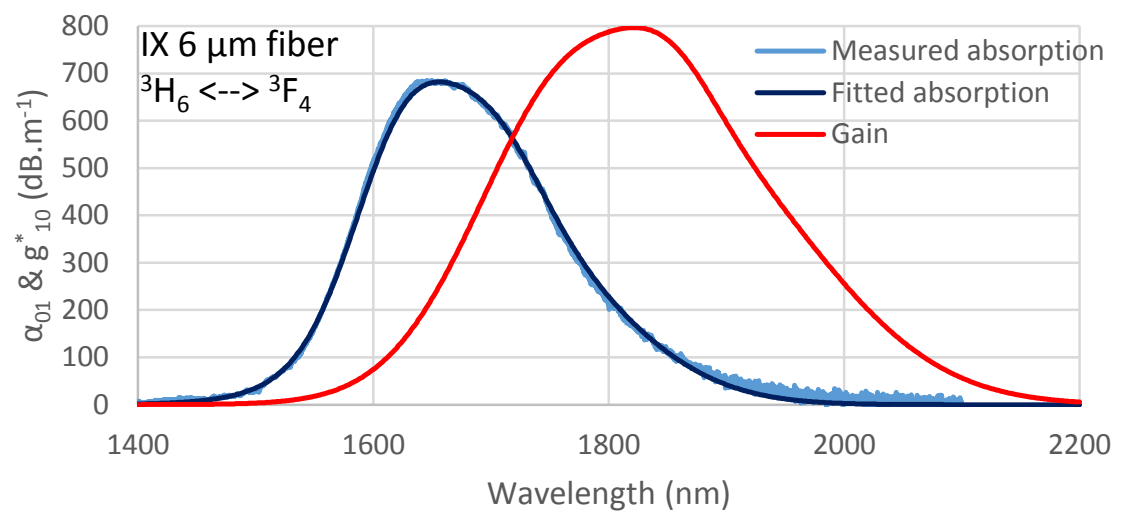

Figure 2: Core absorption and gain coefficients for the IX6 fiber used in the simulations. 


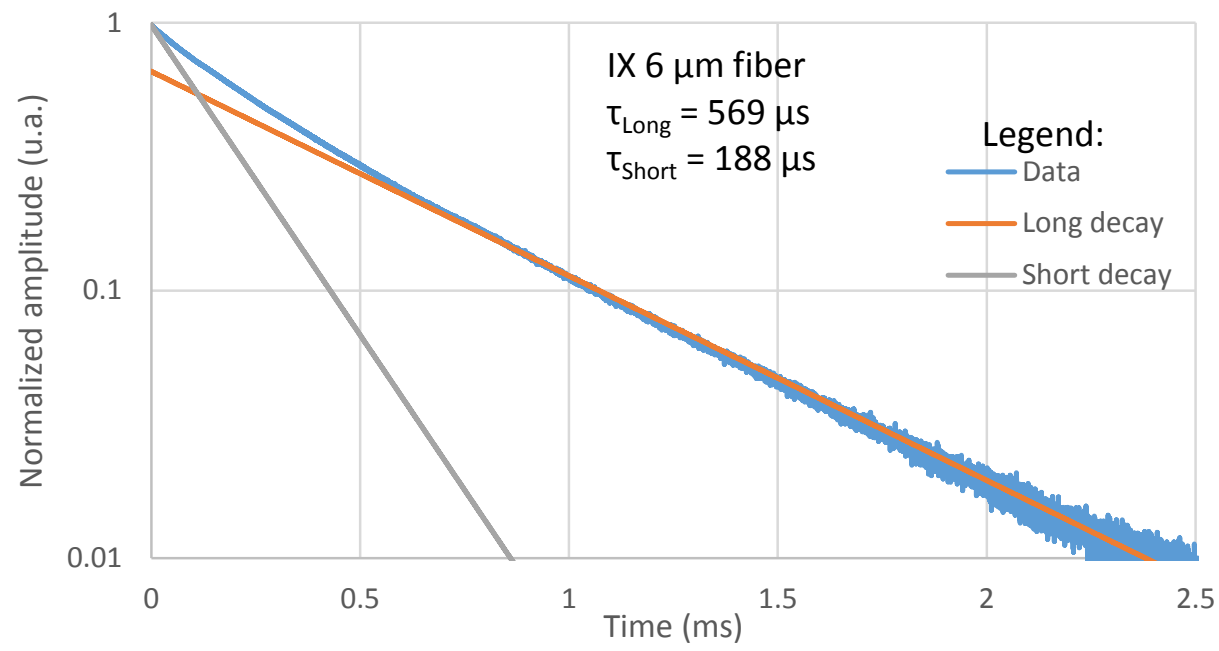

Figure 3: Measured lifetime curve with its two exponential decay curves for the IX6 fiber.

\begin{tabular}{|c|c|c|c|}
\hline Parameter & \multicolumn{2}{|c|}{ Fiber values } & Reference \\
\hline Core diameter & $6 \mu \mathrm{m}$ & $10 \mu \mathrm{m}$ & \multirow{4}{*}{$\begin{array}{c}\text { Manufacturer } \\
\text { datasheet }\end{array}$} \\
\hline Clad diameter & $125 \mu \mathrm{m}$ & $125 \mu \mathrm{m}$ & \\
\hline Core NA & 0.21 & 0.16 & \\
\hline Clad shape & Circular & Octagonal & \\
\hline Overlap factor & $\begin{array}{l}0.69 @ 2050 \mathrm{~nm} \\
0.72 @ 1954 \mathrm{~nm}\end{array}$ & $\begin{array}{l}0.82 @ 2050 \mathrm{~nm} \\
0.84 @ 2050 \mathrm{~nm}\end{array}$ & Calculated \\
\hline${ }^{3} \mathrm{~F}_{4}$ lifetime & $570 \mu \mathrm{s}$ & $500 \mu \mathrm{s}$ & Measured \\
\hline${ }^{3} \mathrm{H}_{4}$ lifetime & \multicolumn{2}{|c|}{$45 \mu \mathrm{s}$} & 16 \\
\hline Cladding pump absorption & 2.52 dB.m ${ }^{-1} @ 793$ nm & 4.05 dB.m ${ }^{-1} @ 793$ nm & Measured \\
\hline $\mathrm{k}_{3011}$ & \multicolumn{2}{|c|}{$1.8 \times 10^{-22} \mathrm{~m}^{3} \cdot \mathrm{s}^{-1}$} & \multirow{2}{*}{9} \\
\hline $\mathrm{k}_{1130}$ & \multicolumn{2}{|c|}{$1.51 \times 10^{-23} \mathrm{~m}^{3} \cdot \mathrm{s}^{-1}$} & \\
\hline Core background loss & \multicolumn{2}{|c|}{$100 \mathrm{~dB} \cdot \mathrm{km}^{-1}$} & 9 \\
\hline Clad background loss & \multicolumn{2}{|c|}{$10 \mathrm{~dB} \cdot \mathrm{km}^{-1}$} & $\begin{array}{c}\text { Manufacturer } \\
\text { datasheet }\end{array}$ \\
\hline Doping level & $4 \times 10^{26} \mathrm{~m}^{-3}$ & $1.72 \times 10^{26} \mathrm{~m}^{-3}$ & $*$ \\
\hline Core absorption ${ }^{3} \mathrm{H}_{6} \rightarrow{ }^{3} \mathrm{~F}_{4}$ & $\begin{array}{l}0.42 \text { dB.m } m^{-1} @ 2050 \text { nm } \\
10.8 \text { dB.m } m^{-1} @ 1954 \text { nm }\end{array}$ & $\begin{array}{l}0.21 \mathrm{~dB} \cdot \mathrm{m}^{-1} @ 2050 \mathrm{~nm} \\
5.39 \mathrm{~dB} \cdot \mathrm{m}^{-1} @ 1954 \mathrm{~nm}\end{array}$ & Measured \\
\hline Core gain ${ }^{3} \mathrm{~F}_{4}->{ }^{3} \mathrm{H}_{6}$ & $\begin{array}{l}133 \text { dB.m }{ }^{-1} @ 2050 \text { nm } \\
398 \text { dB.m }{ }^{-1} @ 1954 \text { nm }\end{array}$ & $\begin{array}{c}68 \text { dB.m }{ }^{-1} @ 2050 \text { nm } \\
198.6 \text { dB.m }{ }^{-1} @ 1954 \text { nm }\end{array}$ & 12 \\
\hline
\end{tabular}

Table 1: Simulation parameters used for the IX6 fiber \& IX10 fiber.

The doping level (*) of the fiber was deduced using the cross section ${ }^{12}$, the absorption measurement and the overlap factor. Assuming the active fiber to be "top hat" (step index and flat overlapping doping region with the core) and a gaussian mode propagation in the core, we can estimate the mode field diameter ${ }^{17}$ and then the overlap factor. 
Since the core composition of the $10 \mu \mathrm{m}$ fiber is different from the $6 \mu \mathrm{m}$ fiber, the cross sections, the efficiency or the temperature dependence (not studied in this paper) will also be different from the $6 \mu \mathrm{m}$ fiber, therefore justifying its evaluation. Since we don't have the gain of the IX10, we did the hypothesis that both active fibers share the same cross sections. The cladding pump absorption was measured to be $4.05 \mathrm{~dB} \cdot \mathrm{m}^{-1}$. Other parameters remain the same.

Even though the pumps are temperature stabilized, the output wavelength shifts with increasing output power. For our pump it was measured to be $0.15 \mathrm{~nm} / \mathrm{W}$ at $25^{\circ} \mathrm{C}$. Despite that, the pump's spectrum is considered monochromatic at 793 $\mathrm{nm}$. In the TDF the pump only sees the measured cladding absorption reported in Table 1 at $793 \mathrm{~nm}$ and its spatial distribution in the cladding is considered homogeneous along the fiber. The input signal spectrum can be either perfect (monochromatic) or we can use the one measured in the setup. Simulations of these two cases are shown later and compared.

The set of 3 level differential population equations ${ }^{9}$ is solved using a stiff solver while the propagation set of differential equations is solved with a Runge-Kutta method ( $4^{\text {th }}$ order). The software takes in account the amplified spontaneous emission (ASE) and is limited to single stage simulation only. The solving time mainly relies on the amount of ASE generated in the setup and stays below 3 minutes (processor of a single laptop) for a single operating point of the given setups.

Good agreement for several single and multistage amplifier topologies at different operating conditions is presented below. The output power and the output spectral shape (signal plus ASE) are both included in the simulations and found to fit the data well. Origins of the difference between theory and experiment are discussed, with emphasis on the accuracy of the cross sections and the cross relaxation parameter. Experimental results and their simulations are measured and calculated for the active fiber, independent of the optical component losses. All the presented amplifiers are operated in saturated mode which means that the signal gain through the amplifier is compressed relative to the small signal limit.

Two Thulium doped double clad fibers were considered for the design of a $10 \mathrm{~W}$ amplifier: $6 \& 10 \mu \mathrm{m}$ core diameters. Both were tested in different design and are presented. Since $2050 \mathrm{~nm}$ is on the long wavelength tail of the measured absorption and gain, the accuracy of these parameters at $2050 \mathrm{~nm}$ might have a stronger impact on the model than at lower wavelengths. Therefore we expect our simulation accuracy to depend on the signal wavelength. The ASE and/or the output power would be affected. The third and last amplifier presented differs from our initial goal, operating at $1954 \mathrm{~nm}$ to test the model at another wavelength.

\section{POWER AMPLIFIER AT 2050 NM BASED ON THE IX6 FIBER}

The first $10 \mathrm{~W}$ amplifier operating at $2050 \mathrm{~nm}$ presented is based on the IX6 fiber. No more than $3 \mathrm{~W}$ of output power has been reported so far for a $6 \mu \mathrm{m}$ core diameter TDF ${ }^{18}$.

\section{a. Setup}

Based on our simulation tool, we demonstrate a design with an output power greater than $10 \mathrm{~W}$ for a multistage amplifier (see Figure 4) with a single-frequency input signal (<30 MHz linewidth) at $2050 \mathrm{~nm}$. The single frequency signal is preamplified to levels between 12 and $670 \mathrm{~mW}$ before being launched in the second or power stage. The power stage is constructed with a $6 \mathrm{~m}$ long IX6 polarization maintaining active fiber. The counter-pumped design was picked to maximize the efficiency of the setup.

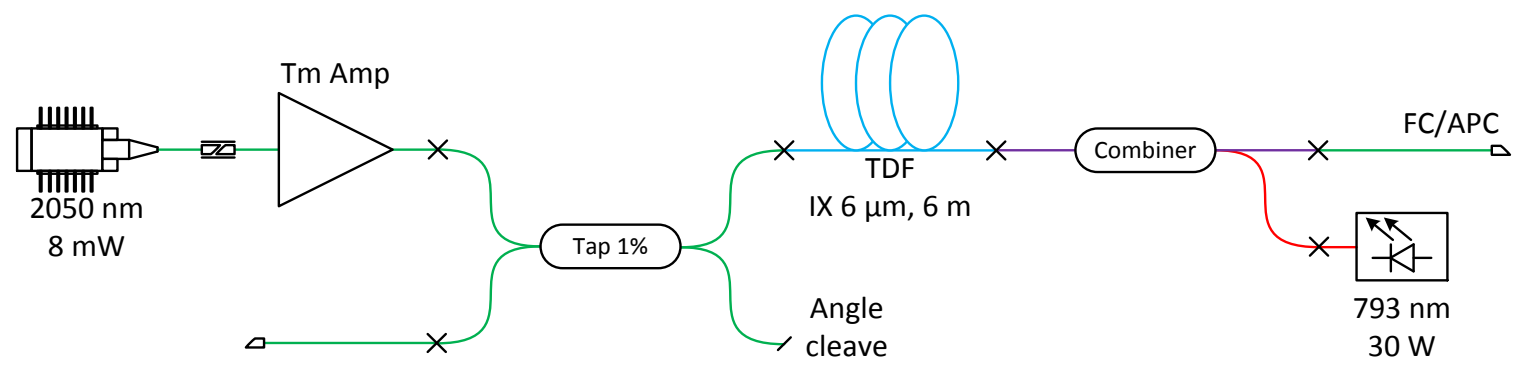

Figure 4: Experimental setup for counter-pumped amplification in an IX6 fiber operating at $2050 \mathrm{~nm}$.

A tap coupler is used to monitor the backward power and spectrum. For stability purposes and thermal dissipation, the active fiber was fastened to a metal heat sink. 


\section{b. Results}

Up to $64 \%$ optical slope efficiency relative to the injected pump is measured in a counter-pumped configuration. The power stage was simulated and its output power is found to be within $5 \%$ of the experimental results (see Figure 5), and is limited only by the launched pump power ( $24 \mathrm{~W}$ of pump is available). Simulation of the two cases, input signal spectrum perfect or input signal spectrum measured, shows negligible differences. Therefore only one simulated case is reported (input measured).

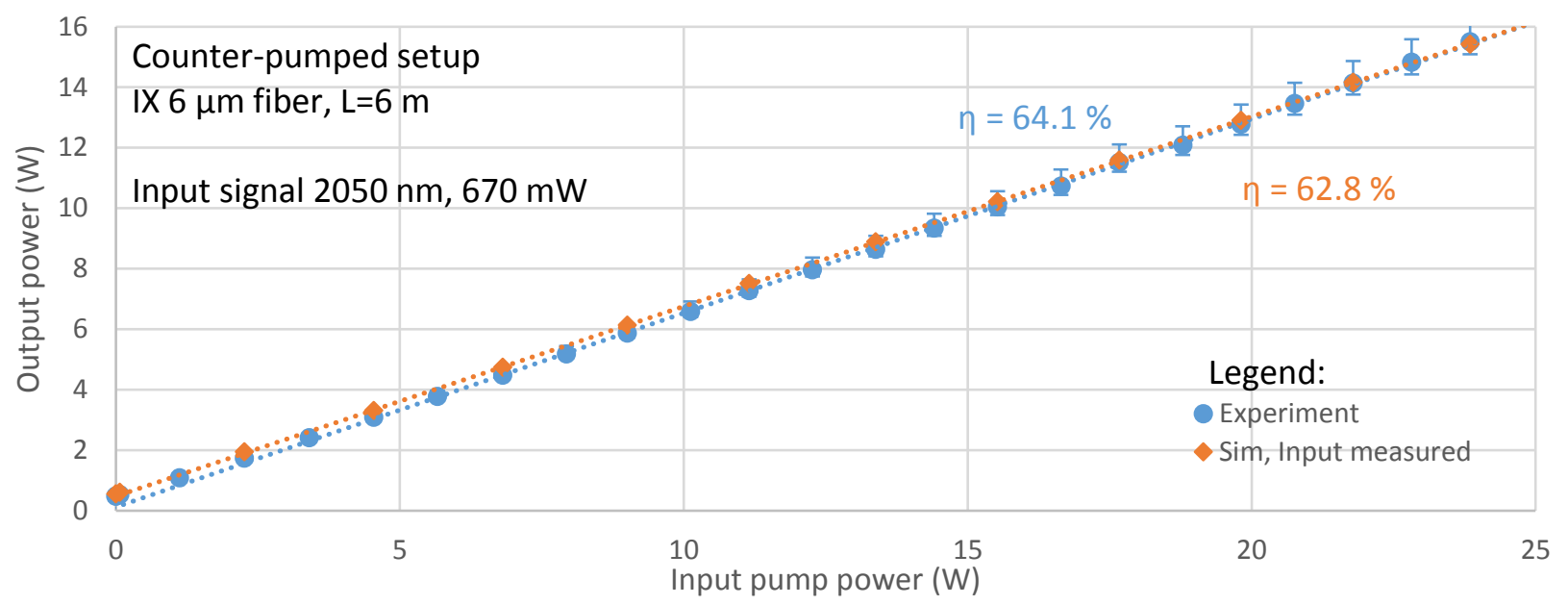

Figure 5: Output power as a function of pump power for an IX6 fiber counter-pumped amplifier.

To our knowledge, this represents the highest output power achieved so far at $2050 \mathrm{~nm}$ using a $6 \mu \mathrm{m}$ core diameter fiber. At the maximum pump power no stimulated Brillouin scattering was observed over an observation period of 24 hours.

Changing the pump power of the pre-amplifier, smaller input powers were injected into the second stage. For the highest launched pump power of $\sim 24 \mathrm{~W}$, the amplifier was lasing limited for input power $<150 \mathrm{~mW}$. At a pump power of $10.1 \mathrm{~W}$ no lasing was observed. The difference between the experimental output power and its simulation for $10.1 \mathrm{~W}$ launched pump power is presented in Figure 6. The error is found to be a function of the input signal power. The simulated threshold pump power exhibits similar behavior.

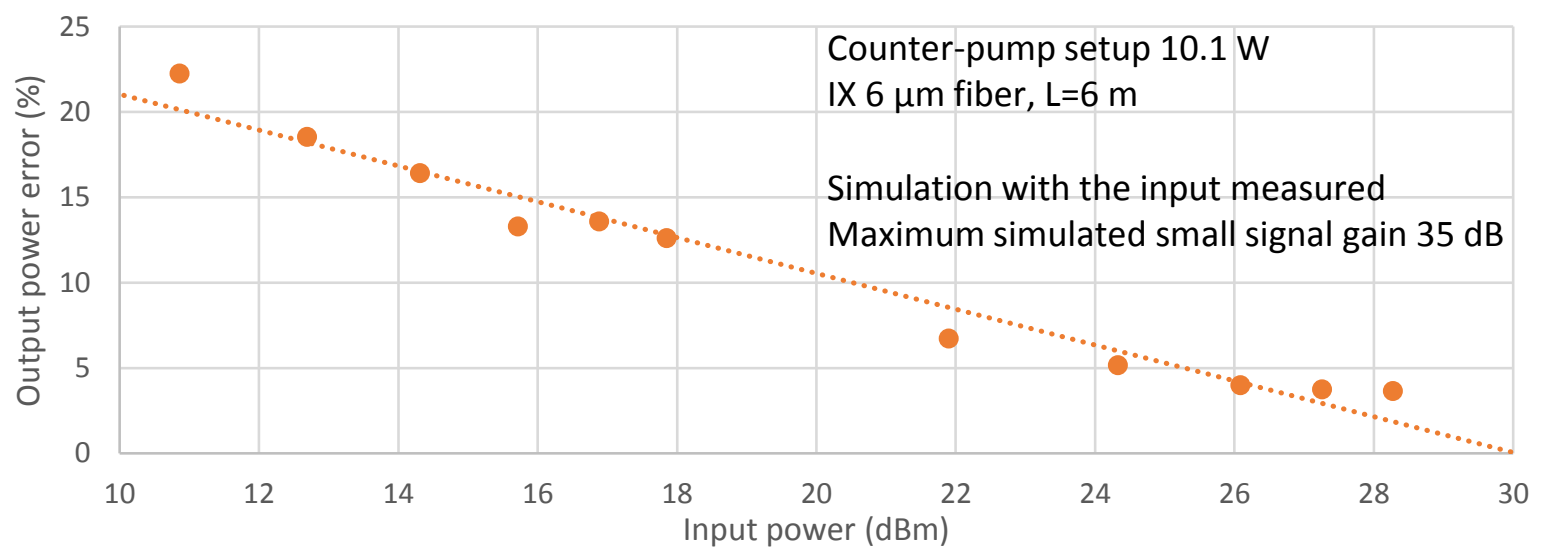

Figure 6: Difference between the measured and simulated output power as a function of input power for an IX6 fiber counter-pumped with a pump power of $10.1 \mathrm{~W}$.

The output spectrum of the amplifier was acquired using a Yokogawa AQ6375 OSA. This acquisition and its simulated output cases are presented in Figure 7 for an input signal power of $61 \mathrm{~mW}$. At these pump and signal power levels, simulation shows that the amplifier gain is reduced by $15 \mathrm{~dB}$ from the unsaturated signal gain of $35 \mathrm{~dB}$ at $2050 \mathrm{~nm}$. Therefore the amplifier is $15 \mathrm{~dB}$ into saturation. A good match is found using the measured output spectrum of the power 
stage. The simulated peak ASE is found to be $2.5 \mathrm{~dB}$ higher in amplitude and $13 \mathrm{~nm}$ shorter in wavelength than the measured ASE spectrum, using the input measured data. The measured optical signal to noise ratio (OSNR) is found to be $47 \pm 1 \mathrm{~dB}$, while the simulated value with the measured input is found to be $48 \mathrm{~dB}$. In contrast, the simulated OSNR with the perfect input is found to be $66 \mathrm{~dB}$, which clearly doesn't fit the experimental data.

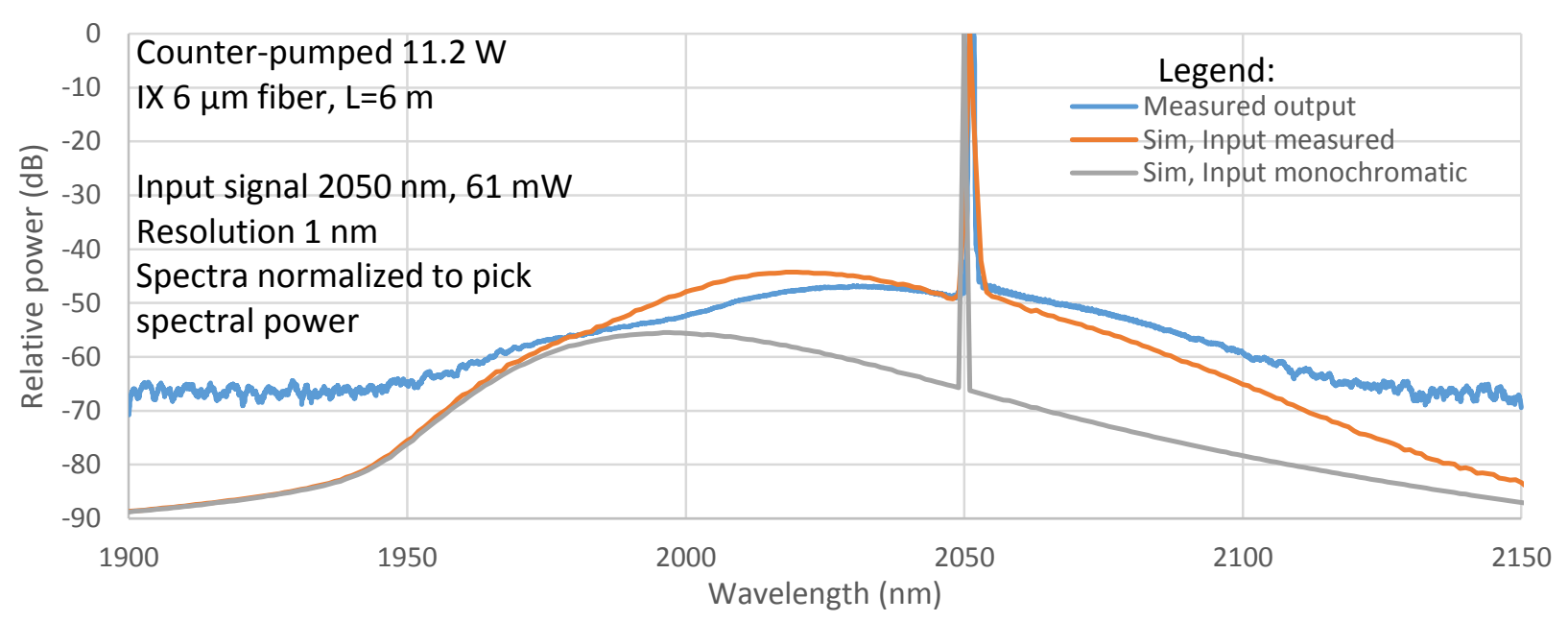

Figure 7: Comparison of experimental and simulated spectra for an IX6 fiber counter-pumped amplifier operating at 2050 $\mathrm{nm}, 15 \mathrm{~dB}$ into saturation.

\section{POWER AMPLIFIER AT 2050 NM BASED ON THE IX10 FIBER}

The second TDF used for a $10 \mathrm{~W}$ amplifier at $2050 \mathrm{~nm}$ is an IX10 fiber. An output power greater than $10 \mathrm{~W}$ has been demonstrated in a similar fiber ${ }^{19}$.

\section{a. Setup}

We demonstrate in this section a second setup able to deliver more than $10 \mathrm{~W}$ of output power. This time the output of the first stage is optically filtered from its ASE using a combination of a circulator and a high reflection fiber Bragg grating (see Figure 8). The signal before the filter had a ratio of signal peak to ASE peak of $56 \mathrm{~dB}$. After the filter the ASE is suppressed by more than $20 \mathrm{~dB}$. This pre-amplifier is now able to deliver $440 \mathrm{~mW}$ into the second stage. The power stage keeps the same pump and topology but uses $8 \mathrm{~m}$ of IX10 non-polarization maintaining active fiber. Like the previous setup, the counter-pumped design was picked to maximize the efficiency of the setup.

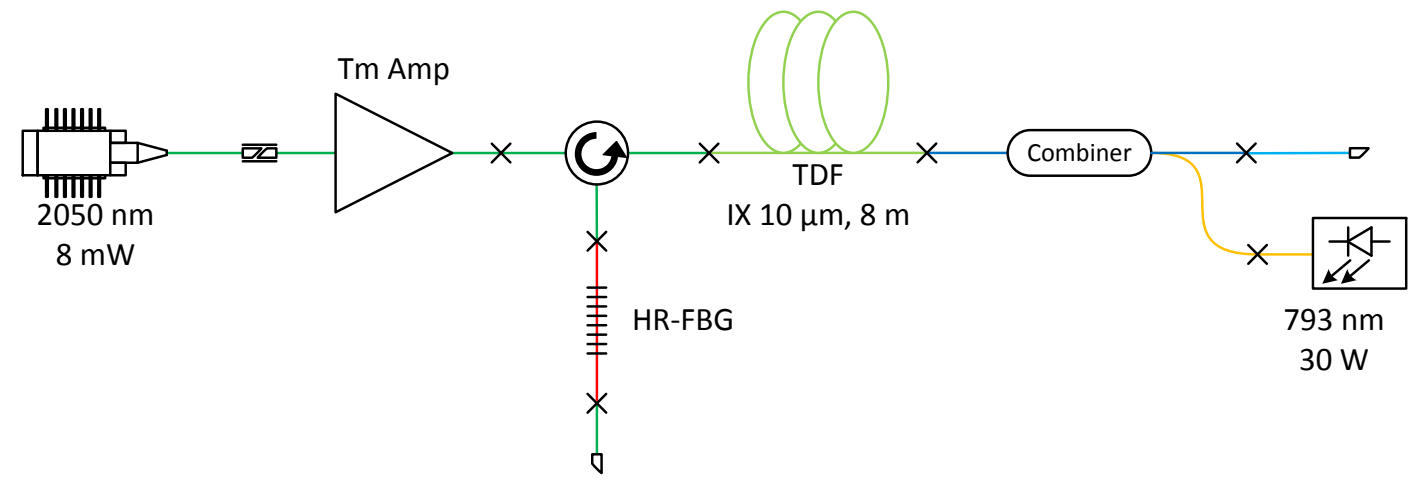

Figure 8: Experimental setup for counter-pumped amplification in an IX10 fiber operating at $2050 \mathrm{~nm}$.

The setup doesn't include a tap coupler to monitor the backward power, because the Brillouin threshold isn't expected to be reached in a $10 \mu \mathrm{m}$ core fiber until an output power of approximately $95 \mathrm{~W}^{1}$. 


\section{b. Results}

This setup is found to have a slope efficiency of $55 \%$ for an input signal power of $440 \mathrm{~mW}$, less efficient than the previous one. The simulated output is found to be within $15 \%$ of the measured one and is displayed with the experimental results in Figure 9. The setup output power is pump power limited.

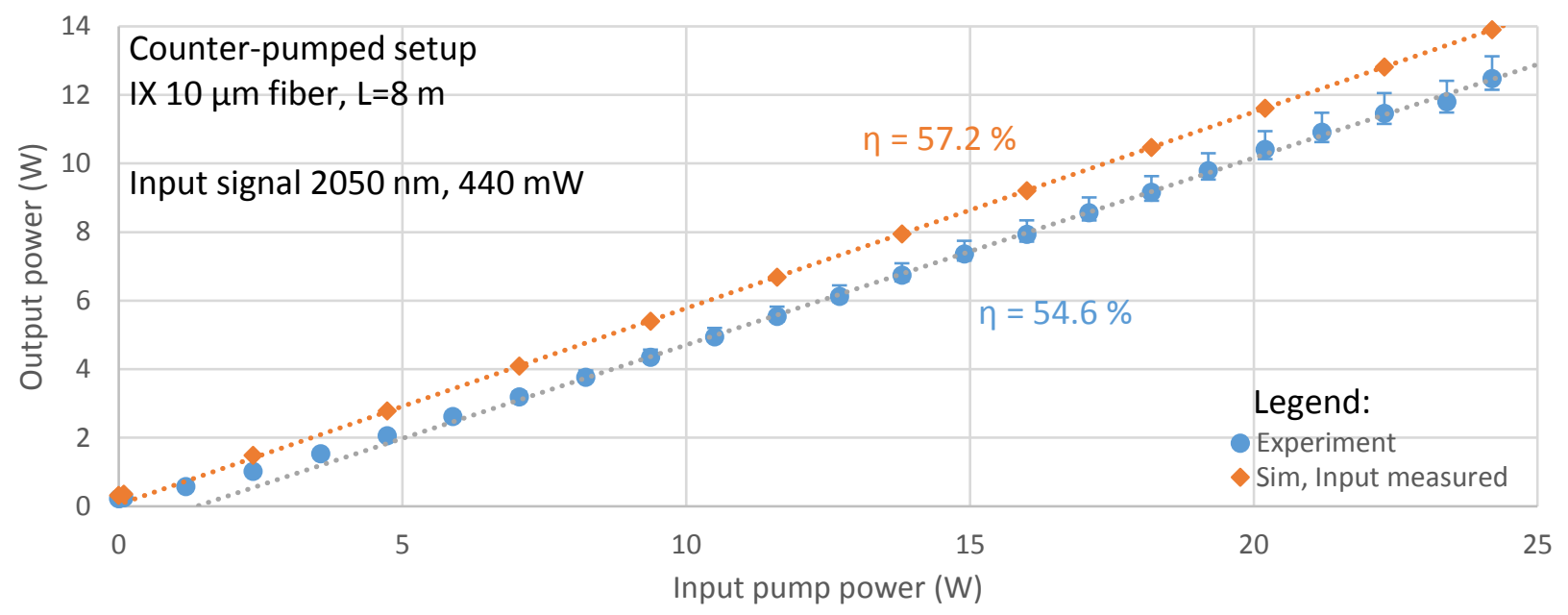

Figure 9: Output power as a function of pump power for an IX10 fiber counter-pumped amplifier.

This amplifier was also tested using a lower input signal power $(35 \mathrm{~mW})$. This simulation exhibits similar behavior as in Figure 9: a lower threshold pump power and a similar slope efficiency. The output power difference slightly increases compared to an input signal power of $440 \mathrm{~mW}$ but remains within $15 \%$. The output spectrum at full pump power was acquired using an OSA, and is displayed with its simulated counterpart in Figure 10. An excellent agreement is found between the two simulated cases. Good agreement is also found between the simulation and the experimental spectrum, where the simulated ASE is slightly over estimated with its peak shifted by $5 \mathrm{~dB}$ in amplitude and - $3 \mathrm{~nm}$ in wavelength with respect to the experimental curve. In this configuration the experimental OSNR is found to be $60 \pm 1 \mathrm{~dB}$ while the simulated values are found to be approximately $3 \mathrm{~dB}$ higher.

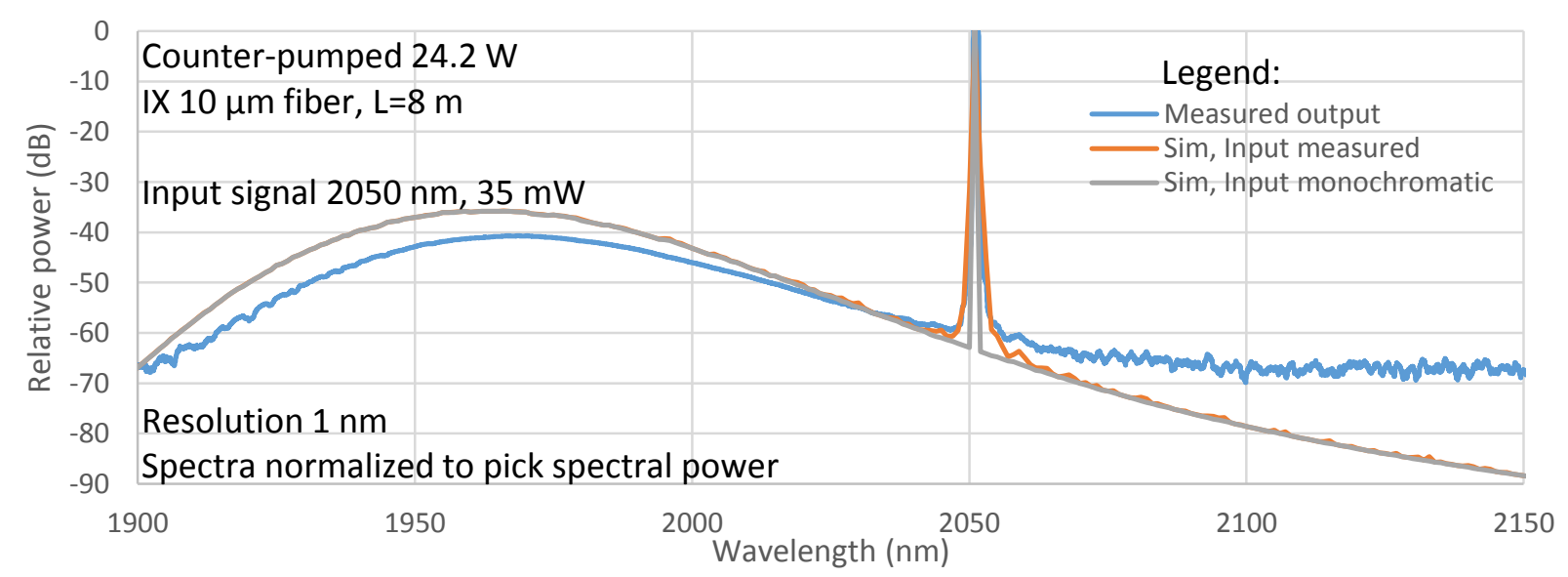

Figure 10: Comparison of experimental and simulated spectra for an IX10 fiber counter-pumped amplifier operating at 2050 $\mathrm{nm}, 7 \mathrm{~dB}$ into saturation.

\section{HIGH GAIN/HIGH POWER AMPLIFIER AT 1954 NM BASED ON THE IX6 FIBER}

The lasing Thulium transition has a broad emission bandwidth ${ }^{20,21}$, allowing us to test the simulation tool at a different wavelength. We employed a single-frequency signal at $1954 \mathrm{~nm}$, a shorter wavelength which should bring better experimental results and give better simulation results. 


\section{a. Setup}

The same IX6 fiber used in section 3 was tested in another setup (see Figure 11) at $1954 \mathrm{~nm}$. We demonstrate here a single stage high gain and high power amplifier clad pumped at $793 \mathrm{~nm}$, able to deliver $35.3 \mathrm{~dB}$ of gain for an input power of 1.3 $\mathrm{mW}$ and $9.4 \mathrm{~W}$ of pump power. The co-pumped design was picked following some comparison of simulation to maximize the output power and OSNR below the signal.

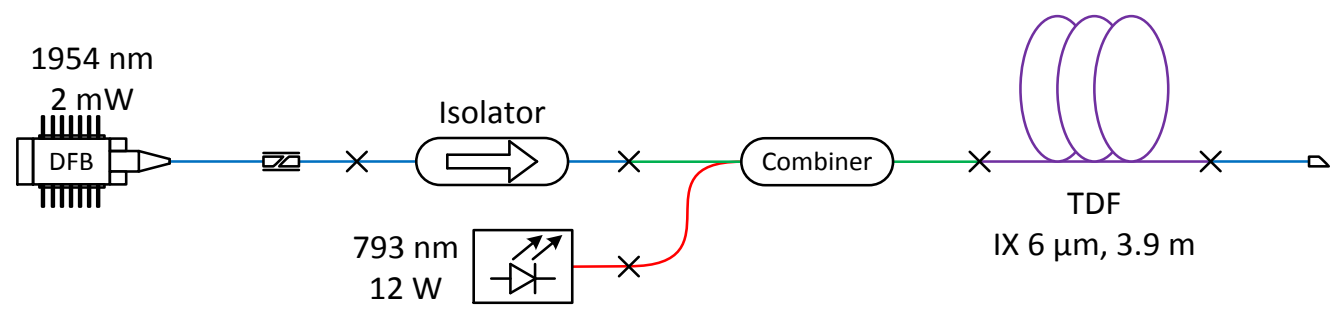

Figure 11: Experimental setup for co-pumped amplification in an IX6 fiber operating at $1954 \mathrm{~nm}$.

\section{b. Results}

The measured output power and its simulation are displayed in Figure 12. Even though the amplifier is designed to be high gain, we still observe a $52 \%$ slope efficiency. At full pump power a difference less than $20 \%$ between experiment and simulation is observed. Like the power amplifier at $2050 \mathrm{~nm}$ (see Figure 6), this is mainly the result of an underestimation of threshold pump power by the simulation.

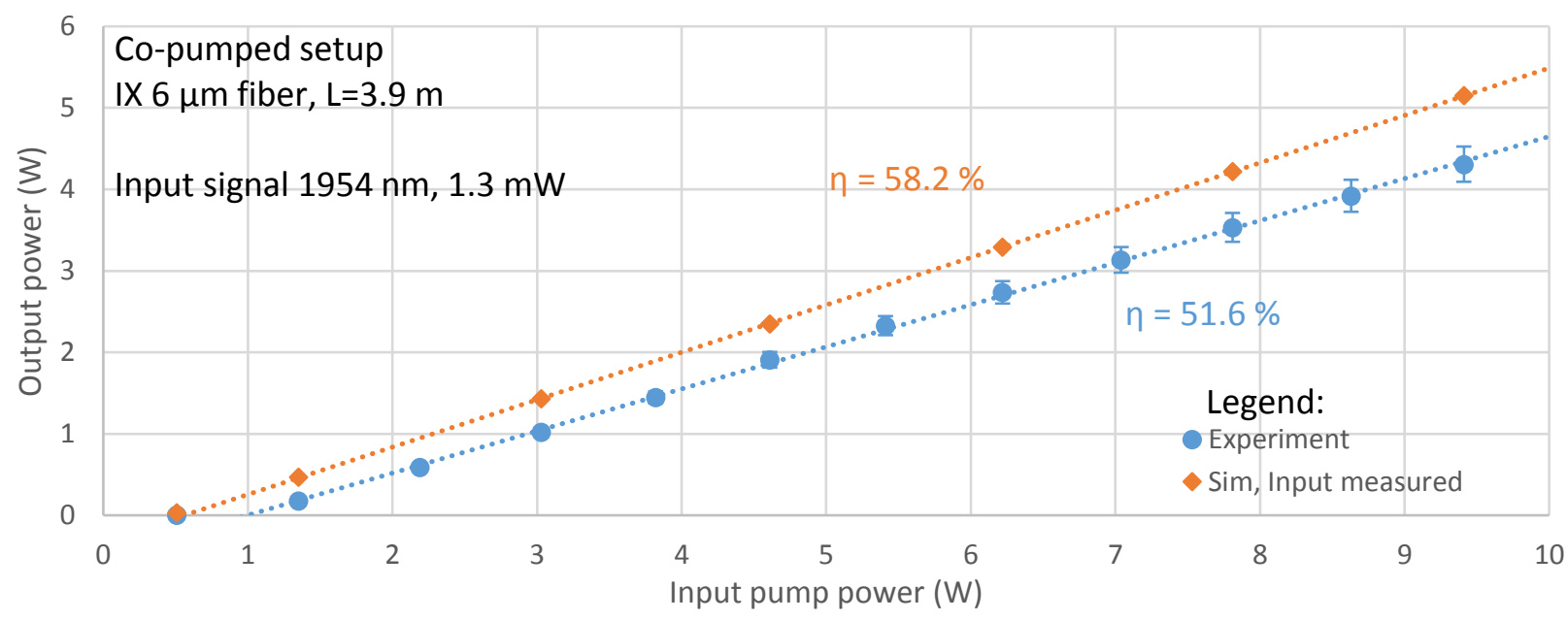

Figure 12: Output power as a function of pump power for an IX6 fiber co-pumped amplifier operating at $1954 \mathrm{~nm}$.

The output spectrum was again acquired and simulated, and the comparison is displayed in Figure 13. It shows a better agreement near the signal than the IX6 fiber amplifier tested at $2050 \mathrm{~nm}$. The difference in the spectra is noticed to increase with the wavelength and is not negligible starting at $2000 \mathrm{~nm}$. The simulated OSNR with the measured input is found to be $45 \mathrm{~dB}$, agreeing well with the measured value of $44 \pm 1 \mathrm{~dB}$. The simulated OSNR with the perfect input is found to be 4 $\mathrm{dB}$ greater. 


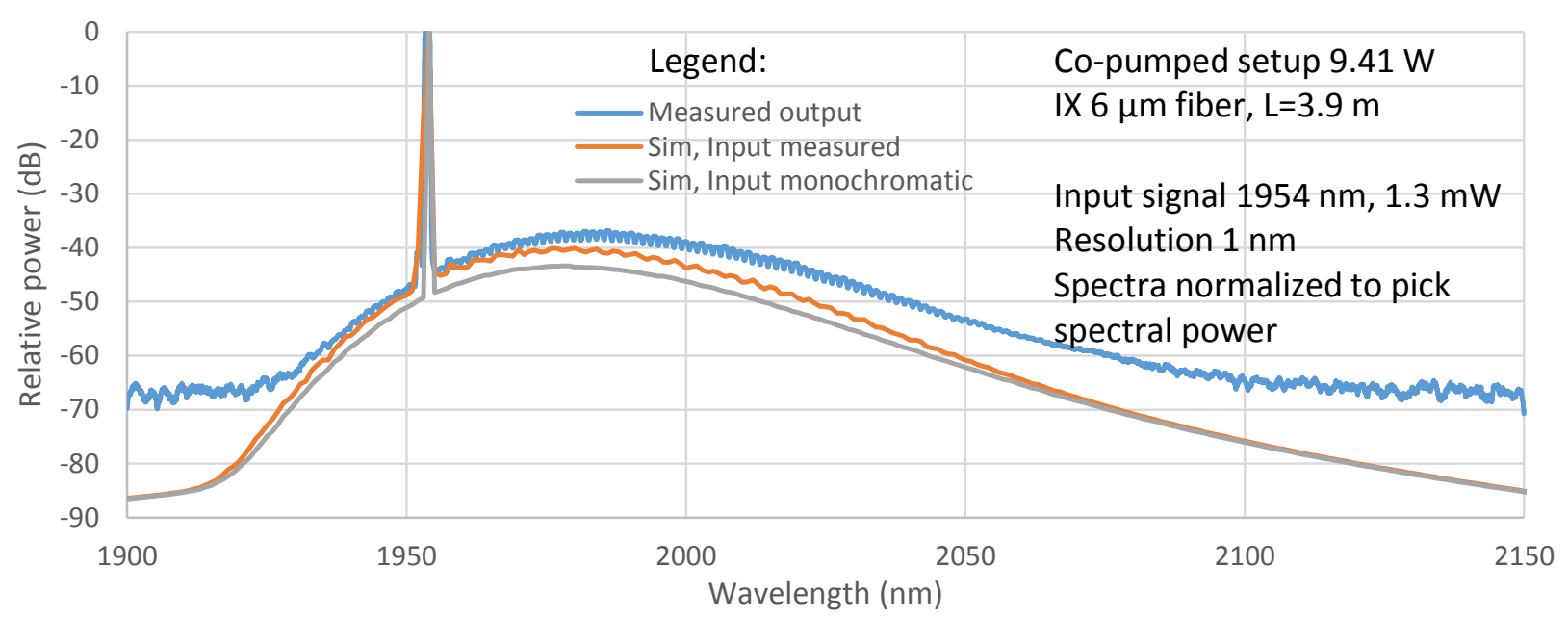

Figure 13: Comparison of experimental and simulated spectra for an IX6 fiber co-pumped amplifier operating at $1954 \mathrm{~nm}$, $24 \mathrm{~dB}$ into saturation.

\section{DISCUSSION}

The comparison of the experimental and simulated results, either spectral output or power output, shows us that the model combined with the selected parameter values (see Figure $2 \&$ Table 1) yields good agreement. From these comparisons we can narrow our consideration to three output parameters: the threshold pump power, the slope efficiency and the spectral output.

In the case of the IX6 fiber, the simulated amplifier performance often underestimates the threshold pump power. The reason for this behavior is unclear. Our hypothesis is that it involves the input saturation level which may be too low in our model. This idea is being investigated.

Without ion-ion interaction in Thulium, the slope efficiency of these amplifiers can't exceed $\approx 40 \%$. But thanks to the "two-for-one" process the maximum efficiency can be doubled to approximately $80 \%$. Our results show that this process is clearly involved, with a slope efficiency as high as $64 \%$ in the IX6 fiber. Since the slope of the simulation matches the experimental slope well in every setup, we can say that the ion-ion parameter values work well for these highly Thulium doped fibers.

The comparison of the experimental and simulated spectra always shows some differences. Among the model parameters, two of the most important for comparison of theory and experiment are the gain and absorption displayed in Figure 2. Since precise and accurate measurements of the cross sections in the $2 \mu \mathrm{m}$ wavelength region are difficult to perform, we attribute the differences between experiment and theory in the output spectra to the accuracy of the cross section measurements. Further work in this area is ongoing to determine the precise nature of the differences between experiment and theory. The comparison also showed us that the ASE of the input signal cannot be neglected. The IX10 fiber might have different cross sections than the IX6 fiber ${ }^{12}$ and this may be enough to explain the spectral differences observed.

For measurements of output power, we note that the theory and experiment agree to within the experimental error of $5 \%$ for the results of a highly saturated amplifier at $2050 \mathrm{~nm}$ signal wavelength shown in Figure 5. For other amplifier configurations, the simulated output power is between $15 \%$ and $20 \%$ higher than the measured output power. We find that the accuracy of our simulations of output power is within about $1 \mathrm{~dB}$ of the measured values of output power for the three amplifier setups studied.

Our measurements and the simulation of the IX10 fiber amplifier showed us that the first 3 meters of the amplifier can be considered as un-pumped. A fully optimized design would thus have only 5 meters of active fiber. Despite that modification in the design, the $10 \mu \mathrm{m}$ amplifier isn't expected to have a better slope efficiency than the IX6 fiber. Thus the IX6 fiber is the best candidate as active fiber for a $10 \mathrm{~W}$ amplifier $2050 \mathrm{~nm}$ operating at room temperature. 


\section{CONCLUSION}

In this paper we presented a simple three level model for a highly doped double clad Thulium alumino-silica optical fiber amplifier. In our model we considered only the most important atomic transitions. We also included two ion-ion processes, the so-called "two-for-one" process and its reverse. Three different double clad amplifiers were presented and their experimental results compared with simulation. Good agreement was found between theory and experiment. The main differences between theory and experiment were in the threshold pump power. This difference seems to be a function of the level of saturation of the amplifier.

We conclude therefore that our simulation provides a design tool accurate to within about $1 \mathrm{~dB}$ for the design of saturated double clad TDF amplifiers up to the maximum measured output signal power of 15 Watts. Our tool allowed us to design two efficient amplifiers with an output power greater than $10 \mathrm{~W}$ at $2050 \mathrm{~nm}$, one with an IX6 and another with an IX10. We deduce that the numerical model accurately represents the physic occurring in highly doped TDFs.

The simulation tool can only simulate a single stage but could be easily scaled to multi-stages. But first it would be interesting to test it with some experimental results of in-band core pumping amplifiers. Such amplifiers could be pumped at two different wavelengths: 1560 and $1940 \mathrm{~nm}$.

We still need to investigate the accuracy of the model at different signal wavelengths with the IX6 with an output power greater than $10 \mathrm{~W}$. The next step will be a detailed study of a highly saturated power amplifier at $1954 \mathrm{~nm}$ or $2004 \mathrm{~nm}$.

\section{ACKNOWLEDGMENT}

The authors would like to acknowledge IX Blue Photonics for supplying the fiber and Thierry Robin for technical discussions. 


\section{BIBLIOGRAPHY}

[1] Lucas, E., Lombard, L., Jaouën, Y., Bordais, S.., Canat, G., "1 kW peak power, $110 \mathrm{~ns}$ single-frequency thulium doped fiber amplifier at $2050 \mathrm{~nm}$," Appl. Opt. 53(20), 4413 (2014).

[2] “OFS Fitel OASiX software.", <http://fiber-optic-catalog.ofsoptics.com/asset/erbium_doped_optical_fiber.pdf >.

[3] “Optiwave Erbium-doped fiber amplifier software.”, <https://optiwave.com/resources/applicationsresources/optical-system-optimizing-the-edfa-gain-for-wdm-lightwave-systems/>.

[4] Giles, C. R.., Desurvire, E., "Modeling erbium-doped fiber amplifiers," J. Light. Technol. 9(2), 271-283 (1991).

[5] Bolshtyansky, M., Wysocki, P.., Conti, N., "Model of temperature dependence for gain shape of erbium-doped fiber amplifier," J. Light. Technol. 18(11), 1533-1540 (2000).

[6] Hu, Z.-Y., Yan, P., Xiao, Q.-R., Liu, Q.., Gong, M.-L., "227-W output all-fiberized Tm-doped fiber laser at 1908 nm," Chinese Phys. B 23(10), 104206 (2014).

[7] Khamis, M. A.., Ennser, K., "Model for a Thulium-Doped Silica Fiber Amplifier Pumped at $1558 \mathrm{~nm}$ and 793 nm,” IJEAT 5(4), 76-80 (2016).

[8] Smith, A. V.., Smith, J. J., "Mode instability thresholds for Tm-doped fiber amplifiers pumped at $790 \mathrm{~nm}$," Opt. Express 24(2), 975 (2016).

[9] Jackson, S. D.., King, T. A., “Theoretical modeling of Tm-doped silica fiber lasers,” J. Light. Technol. 17(5), 948-956 (1999).

[10] Walsh, B. M.., Barnes, N. P., "Comparison of Tm : ZBLAN and Tm : silica fiber lasers; Spectroscopy and tunable pulsed laser operation around 1.9 m," Appl. Phys. B Lasers Opt. 78(3-4), 325-333 (2004).

[11] Jackson, S. D.., Mossman, S., "Efficiency dependence on the Tm3+ and Al3+ concentrations for Tm3+-doped silica double-clad fiber lasers.," Appl. Opt. 42, 2702-2707 (2003).

[12] Renard, W., "Etude et réalisation de sources lasers fibrées impulsionnelles de forte puissance autour de $2 \mu \mathrm{m}$," ParisTech (2012).

[13] Agger, S. D.., Povlsen, J. H., "Emission and absorption cross section of thulium doped silica fibers.," Opt. Express 14, 50-57 (2006).

[14] Moulton, P. F., Rines, G. A., Slobodtchikov, E. V., Wall, K. F., Frith, G., Samson, B.., Carter, A. L. G., “TmDoped Fiber Lasers: Fundamentals and Power Scaling,” IEEE J. Sel. Top. Quantum Electron. 15(1), 85-92 (2009).

[15] Simpson, D. A., "Spectroscopy of thulium doped silica glass" (2008).

[16] Peterka, P., Faure, B., Blanc, W., Karasek, M.., Dussardier, B., "Theoretical modelling of S-band thulium-doped silica fibre amplifiers," Opt. Quantum Electron. 36, 201-212 (2004).

[17] Marcuse, D., "Gaussian approximation of the fundamental modes of graded-index fibers," J. Opt. Soc. Am. 68(2), 103 (1978).

[18] Creeden, D., Johnson, B. R., Rines, G. A.., Setzler, S. D., "Resonant tandem pumping of Tm-doped fiber lasers," Technol. Def. Secur. X, 90810I (2014).

[19] Ehrenreich, T., Khitrov, V., Frith, G., Farroni, J., Farley, K., Tankala, K., Carter, A., Christensen, S., Samson, B., et al., "High Efficiency 20W Single Frequency PM Fiber Amplifier at 2037nm," Adv. Solid-State Photonics (2009).

[20] Li, Z., Jung, Y., Daniel, J. M. O., Simakov, N., Shardlow, P. C., Heidt, A. M., Clarkson, A., Alam, S.-U.., Richardson, D. J., "Extreme Short Wavelength Operation $(1.65-1.7 \mu \mathrm{m})$ of Silica-Based Thulium-Doped Fiber Amplifier," Opt. Fiber Commun. Conf. 1, Tu2C.1, OSA, Washington, D.C. (2015).

[21] Jin, X., Du, X., Wang, X., Zhou, P., Zhang, H., Wang, X.., Liu, Z., "High-power ultralong-wavelength Tmdoped silica fiber laser cladding-pumped with a random distributed feedback fiber laser," Sci. Rep. 6, 30052 (2016). 